\title{
Una mirada al Greater London Council. Una experiencia creativa de democracia local
}

\author{
Rafael Rodríguez Prieto \\ José María Seco Martínez \\ Universidad Pablo de Olavide de Sevilla. Facultad de Derecho \\ jmsecmar@upo.es \\ rrodpri@upo.es
}

\section{Resumen}

Esta experiencia de democracia local ha sido el experimento europeo más ambicioso hasta la fecha en gobiernos democrático-participativos. Influido por los movimientos sociales de los setenta y pilotado por la corriente de izquierda más crítica del Partido Laborista, llevó a término alianzas con los movimientos sociales y dio autonomía a los diferentes colectivos - mujeres, homosexuales y etnias - para que pudieran participar con libertad en la toma de decisiones. Con competencias muy limitadas y un presupuesto anual de 800 millones de libras, el Greater London Council marcó un hito en la historia de las relaciones de los movimientos sociales con la Administración pública.

Palabras clave: participación, democracia local, movimientos sociales, producción, utilidad social.

\section{Abstract. A look to the Greater London Council. A creative experience of local democracy}

This experience of local democracy has been so far the most ambitious European experiment in democratic/participatory governments. Influenced by the social movements of the seventies and leaded by the most critical left of the Labour Party, it brought alliances with the social movements to a conclusion, it gave autonomy to different groups -women, homosexual and ethnic groups - so that they could participate with freedom in the decisionmaking. With very limited competitions and an annual budget of 800 million pounds, the Greater London Council marked a milestone in the history of the relations between the social movements and the civil service.

Key words: participation, local democracy, social movements, production, social utility.

\section{Sumario}

\section{Introducción 4. A modo de conclusión}

2. La nueva izquierda en acción: Greater Bibliografía London Council. Una visión general

3. De por qué es necesario hablar de políticas radicales en el Greater 


\section{Introducción}

En 1986, el gobierno neoliberal de Margaret Thatcher abolió el Greater London Council. Fue un ataque inédito contra la autonomía local, que ponía fin a una institución democrática que gozaba del apoyo y el reconocimiento de buena parte de los londinenses. Atrás quedaba una experiencia de gobierno local que había logrado escenificar políticas más creativas y abiertas a la participación y a la decisión de los ciudadanos y de los movimientos sociales.

En 1979, llegaba al poder un gobierno conservador, con Margaret Thatcher a la cabeza. El ascenso de la "dama de hierro" marcaría un antes y un después en la política europea del siglo XX. Sus políticas radicalmente opuestas al por entonces incuestionable Estado de bienestar constituyeron el arranque político de un modelo de estado decisivamente distinto, demasiado afín a sistemas de regulación más adaptables a los intereses sistémicos del mercado (libre circulación de capitales, potenciación de la oferta, investigación y desarrollo tecnológico, flexibilización de los mercados de trabajo, descentralización empresarial, etc.). Digamos que Thatcher emprendió el reagrupamiento táctico del bloque histórico dominante en una lucha por la transformación hegemónica de las relaciones entre la sociedad y el poder, mediante la apropiación de las estrategias y consignas de la tradición popular y su oposición a cualquier política social ${ }^{1}$. Como correlato a este reagrupamiento, la izquierda parlamentaria tradicional entraba en una fase de confusiones y descensos sucesivos, que se materializaría en la caída, con sus resistencias y revoluciones populares, del bloque soviético en 1989.

Empero, junto a este modelo de izquierda convencional, existía otra izquierda muy distinta, cuyos orígenes se remontaban a los últimos años de la década de 1960 en un contexto generalizado de reacciones y denuncias de los movimientos estudiantiles. La actitud de esta otra corriente de izquierda frente a los partidos comunistas y social-demócratas fue frontal, y sus registros, desde luego, bastante críticos. A los primeros les reprochaba sus lealtades al régimen soviético, a los segundos, que se solidarizaran con los valores burgueses, sin apenas cuestionar los límites representativos de los sistemas democráticos liberales $^{2}$. El Greater London Council (GLC) fue la respuesta a estas ideas. La prueba de que las alternativas, en este caso la autonomía de los trabajadores y trabajadoras, eran posibles. Esta experiencia de democracia local, parafraseando a Hilary Wainwright — antigua activista de GLC—, significó el más ambicioso experimento europeo en gobiernos democrático-participativos hasta la fecha. Influido por los movimientos sociales de la década de 1970 y pilotado

1. Baratta, G., Las rosas y los cuadernos: El pensamiento dialógico de Antonio Gramsci, Bellaterra, Barcelona, 2003, p. 217.

2. Junto a ello, dos momentos históricos en Europa simbolizarían el auge y la caída de esta nueva izquierda: la revolución checa y la revolución de los claveles en Portugal. La primera fue hundida por la violencia del capitalismo de Estado de la extinta URSS y la otra, por la presión del capitalismo corporativo de EEUU y la socialdemocracia alemana a través del líder socialdemócrata Mario Soares. Véase Livingstone, K., Ali, T., Who’s afraid of Margaret Thatcher, op. cit., 1984, p. 24-25. 
por una izquierda radical, llevó a término alianzas con los movimientos sociales y dio autonomía a los diferentes colectivos para que pudieran participar con libertad en la toma de decisiones ${ }^{3}$. Con competencias limitadas y un presupuesto anual de 800 millones de libras, el GLC, con casi 22.000 empleos a su cargo, marcó un hito en la historia de las relaciones de los movimientos sociales con la Administración pública.

Debemos comenzar, pues, este relato preguntándonos ¡en qué consistió el GLC? ¿Cuáles fueron sus innovaciones en materia de gestión popular y participación ciudadana? ¿Qué significaciones tuvo aquella experiencia local radical de la administración laborista en el gobierno de Londres y su área metropolitana a comienzos de los ochenta (1981 a 1986)?

\section{La nueva izquierda en acción: Greater London Council. Una visión general}

Después de la Segunda Guerra Mundial, la política británica atravesó una singladura política de comprensión y entendimientos entre el ala derecha del Partido Laborista y los conservadores moderados. Dos momentos históricos fueron decisivos para que la quiebra definitiva de este "compromiso histórico por la Inglaterra postbélica», que diría Stuart Hall ${ }^{4}$, fuera un hecho: (1) el fracaso de una candidatura de consenso al liderazgo del Partido Laborista, que pudiera satisfacer tanto a moderados como a electores de izquierda, y (2) la emergencia del thatcherismo y sus políticas monetaristas 5 .

Pero, entretanto se escenifica esta ruptura, emergen con fuerza en el Partido Laborista dos figuras clave para el GLC: Tony Benn y Ken Livingstone. Ambos representaban a la nueva izquierda británica, llamada a romper con las inercias centristas del laborismo ${ }^{6}$. La importancia de estas dos figuras venía marcada por su compromiso directo con los movimientos sociales y las prácticas populares a nivel local, protagonizadas por toda clase de movimientos sociales - de mujeres, de minorías étnicas, de gays y lesbianas, de ecologistas, entre otros ${ }^{7}{ }^{7}$. El

3. Wainwright, H., Reclaim the State: Experiments in Popular Democracy, Nueva York, Verso, 2003, p. 7.

4. BaratTA, G., Las rosas y los cuadernos: El pensamiento dialógico de Antonio Gramsci, op. cit., p. 217.

5. Ambos factores se interrelacionan según Richard Gott. La falta de un liderazgo capaz de ilusionar al electorado y a los movimientos sociales — como podría haber sido el de Tony Benn y el triunfo de las tesis centristas - sumieron al Partido Laborista en una grave crisis de identidad. Véase Livingstone, K., Ali, T., Who's afraid of Margaret Thatcher, Londres, Verso, 1984, p. 132-134.

6. Ídem, p. 23. De hecho, no dudaron lo más mínimo en realizar una crítica abierta al capitalismo como sistema productivo durante las elecciones de 1983 en el marco de la grave crisis económica que asolaba Inglaterra.

7. El socialismo se entendió como un proceso hacia un autogobierno real, un camino hacia la transformación del capitalismo y el desarrollo dentro de un mundo donde el imperialismo y el armamentismo desaparecieran. Véase CHUN, L., The British New Left, Edimburgo, Edinburgh University Press, 1993, p. 193. 
objetivo era posibilitar una gran coalición, pero no como una mera concentración de fuerzas que reprodujeran los viejos "consensos de poder", sino como una red con capacidad de aportar alternativas creíbles para el conjunto del cuerpo electoral. Una coalición que no se detuviera sólo en las infidelidades y falsedades del capitalismo o en las disputas y regresiones del sistema político, sino que propusiera prácticas democráticas radicales y relaciones productivas justas 8 .

El hecho de que el GLC fuera el resultado de la convergencia de un amplio espectro de fuerzas sociales de nueva izquierda, entre las que se encontraban el movimiento de mujeres, las minorías étnicas, los sindicatos y los movimientos vecinales, propició: (1) la difusión de sus experiencias de participación ciudadana fuera de Londres, y (2) que se interpretara como el renacimiento de la izquierda mediante la concreción política de los esfuerzos de los movimientos sociales. Al cabo, se trataba de una experiencia con la que se sentían identificados, no ya la ciudadanía londinense (exceptuando las clases sociales privilegiadas dominantes), sino todo el país ${ }^{9}$.

Este movimiento, por tanto, se entendió como el punto de partida de un tercer camino ${ }^{10}$ — que no hay que confundir con la tercera vía (third way) de Blair- ${ }^{11}$ entre la vía socialdemócrata y el socialismo real. Esto es, como punto de arranque de un proceso más amplio, en el que los ciudadanos pudieran ejercer sus responsabilidades y elegir su destino, controlando los medios y participando en la vida pública. Se trataba no sólo de construir un nuevo gobierno,

8. En este sentido, Hilary Wainwright señalaba, en un trabajo sobre el Partido Laborista y la incidencia que los movimientos sociales tuvieron sobre el mismo, que, durante la primera mitad de la década de 1970, las iniciativas más transformadoras en el ámbito del socialismo no soviético habían venido desde fuera del Partido Laborista, es decir, desde las experiencias locales, prácticas sindicales como las de Lucas Aerospace, el movimiento de liberación de mujeres, los ecologistas y las alternativas culturales. Es preciso evolucionar a un nuevo tipo de partido que aúne diversidad y transformación social. Véase WAINWRIGHT, H., Labour. A Tale of Two Parties, Londres, 1987, p. 4, 270, 286.

9. KNIGHT, C., WISE, V., «Editorial: Taking to the Streets», London Labour Briefing, marzo de 1982 , p. 3.

10. El proyecto de la third road era unir al fragmentario movimiento social para constituir un proyecto de futuro donde se recogieran las aspiraciones de estos grupos. Así se crearía una dinámica entre estos movimientos y los tradicionales de clase. El fin era buscar la unidad para cambiar la sociedad desde las diferencias. No desde la homogeneización del marxismo tradicional, ni desde la fragmentación postmoderna que apaga la potencia reivindicativa y rupturista de las políticas. A derecha e izquierda en el seno del partido laborista se criticó esta opción.

11. Para profundizar en las diferencias entre la nueva izquierda (New Left) y el nuevo laborismo (New Labour) de Blair, véase PANITCH, L, LEYs, C., The End of Parliamentary Socialism: From New Left to New Labour, op. cit., p. 237-260. Para la izquierda surgida de los movimientos sociales de los sesenta y setenta - llamada New Left_-, la democratización radical del Estado y la economía era la precondición necesaria para acabar con las injusticias del capitalismo. La derrota de la New Left en el Partido Laborista y el posterior auge de la tercera vía de Blair, dirigida a reforzar el lado más derechista del laborismo británico, acabó con la esperanza que significaron dichos movimientos. La conclusión es que lo que hoy se llama «nuevo laborismo» no es otra cosa que la sublimación de las viejas posiciones conservadoras del Partido Laborista. 
sino además de hacer un nuevo partido identificado con todos aquellos sectores tradicionalmente olvidados en las políticas públicas e integrar en el mismo las aspiraciones de los movimientos sociales. El objetivo no consistía únicamente en mantener la unidad de la clase trabajadora, sino en profundizar en el autogobierno y en la conquista de espacios públicos de acción colectiva, abiertos a la participación de otras capas de la población. Se trataba de avanzar más allá de las políticas de izquierda tradicionales, dando entrada a movimientos sociales y a otras iniciativas que hicieran a la democracia más real, esto es, más transparente y participativa. No en vano, el GLC rompía los límites tradicionales del Partido Laborista y se dirigía a todo tipo de personas con preocupaciones sociales — desempleados, lesbianas y homosexuales, indigentes, intelectuales de izquierda, clase media con sensibilidad social—. La clase social era el eje crucial de sus políticas, el pivote de toda su reforma social. El GLC representaba por aquellos días, como bien apunta Anthony Barnett, el fin del laborismo y el comienzo del socialismo en el Reino Unido ${ }^{12}$.

Con la irrupción de Tony Benn y Ken Livingstone como dirigentes del Partido Laborista en Londres, el GLC comienza a ocupar lugares destacados en la vida política y cultural londinense ${ }^{13}$. Acciones como la lucha contra las políticas de exclusión de las minorías o el incremento de las tarifas de transporte público, amén de la promoción de sus iniciativas políticas con el objeto de ampliar su base social, lo harían muy popular ${ }^{14}$. Así, por ejemplo, dio a conocer, con vallas publicitarias, el alcance de sus propuestas y denunció las políticas del gobierno conservador ${ }^{15}$; llevó a cabo conciertos de rock llamados «empleos por un cambio» en los que participaba gran número de londinen$\operatorname{ses}^{16}$. Era una forma de ampliar su respaldo social entre los londinenses y de dar a conocer las políticas locales más a allá de los límites tradicionales del laborismo. Para los activistas del GLC resultaba claro que, para transformar el Reino Unido, había que volcar el corazón de los jóvenes. Era preciso, por tanto, dar a conocer, para luego implicar, el proyecto del GLC. Se trataba, en suma, de educar primero para acercar después el ejecutivo local a los ciudadanos. Precisamente, la educación reglada fue una competencia que compartieron con la Inner London Education Authority e, incluso, dispusieron de competencias específicas en la elaboración de planes estratégicos y de ocio.

$Y$ es que la estrategia de construir nuevos espacios públicos para fortalecer el autogobierno y el civismo responsable de la ciudadanía era central para el GLC. Había que conocer las necesidades de la gente y explicar las políticas que se hacían de manera eficaz. En el marco de esta proyección de la imagen

12. Barnett, A., "Whistling in the Wind?», New Socialist, enero, 1986, p. 20.

13. Ward, M., "Labour’s Capital Gains: The GLC Experience», Marxism Today, 1983, p. 29.

14. Fielding, N., SeYd, P., "Cities in the Revolt», New Socialist, septiembre, 1984, p. 36.

15. Véase Wheen, F., The Battle for London, Londres, Pluto, 1985; HipKIN, B., "Writing on the Wall for the GLC», Marxism Today, agosto, 1984, p. 34-38.

16. Mackintosh, M., Wainwright, H. (ed.), A Taste of Power, Londres, Verso, 1987, p. 371 y 383 . 
del GLC, se declaró el año 1984 como «el año contra el racismo», apelando a los londinenses a que formaran parte de la solución, a menos que quisieran seguir siendo parte del problema. Si los conservadores promovían una imagen de estampa de Londres con el Buckingham Palace y el cambio de guardia como resumen de la grandeza del Reino Unido, el GLC de Livingstone promocionaba el Londres lírico, cultural y diverso ${ }^{17}$, haciendo de la capital inglesa una ciudad para la diversidad, donde las diferencias debían ser entendidas como enriquecimiento y, sobre todo, como posibilidad para una educación en la ciudadanía. Había que evitar el miedo a las fricciones entre comunidades y colectivos ciudadanos —desempleados, negros, homosexuales, inmigrantes, etc.—, el miedo «a ser tocados», que diría Canetti ${ }^{18}$.

Poco a poco se fue haciendo con el apoyo de los sectores menos favorecidos de la población, al tiempo que se ampliaba la base social de las llamadas «clases populares». Por una parte, el crecimiento de los movimientos de mujeres, ecologistas, pacifistas..., y, por otra, el rejuvenecimiento de los mecanismos de cooperación comunitaria, cuestionaron el concepto tradicional de clase, incapaz por más tiempo de contener la potencia heterogénea de todo el movimiento ${ }^{19}$. Entre otras cosas, porque la relación del GLC con los movimientos sociales no era instrumental. La fuerza de Livingstone y la izquierda laborista en el Labour Party suscitó fuertes adhesiones de movimientos extraparlamentarios. No hay que olvidar que muchos de sus integrantes habían abandonado tiempo atrás el Partido Laborista para trabajar en el seno de movimientos sociales. Merced a la experiencia del GLC, viejos militantes del Partido Laborista emprendieron el camino de regreso. Estos grupos trajeron consigo otro tipo de militancia más democrática y participativa, con voluntad de cambio, esto es, de transformar la realidad ${ }^{20}$.

\section{De por qué es necesario hablar de políticas radicales en el Greater London Council}

Fue en 1981 cuando el Partido Laborista, liderado por Ken Livingstone, accedió a la alcaldía de Londres con un programa electoral y un compromiso público no conformista. Su objetivo político, lejos de limitarse a la redistribución de los recursos entre la población, no era otro que transformar la realidad social mediante el autogobierno de los ciudadanos a través de prácticas cívicas continuas. El hecho de que dos años antes, en 1979, la izquierda del Partido Laborista se hiciera con la dirección del partido a nivel regional de Londres y asumiera estrategias de lucha contra las políticas de Thatcher, desde la recons-

17. Campbell, J., Goodbye to the GLC, op. cit., p. 8.

18. Véase CanetTi, E., Masa y poder, Barcelona, Muchnik Editores, 2000, p. 9.

19. «Editorial: Realignments on the Left», Chartist, mayo-junio, 1985, p. 3.

20. "The Women's Movement and The Labour Party: An Interview with Labour Party Feminists», Feminist Review, 16, 1984, 75-87. GyFORD, J., "From Community Action to Local Socialism", Local Government Studies, 10, 1984, p. 5-10. 
trucción de un GLC más creativo y comprometido con el carácter multiétnico de Londres y los movimientos sociales, facilitó el triunfo electoral ${ }^{21}$.

El modelo de sociedad política que anticipaba el GLC pretendía restaurar el valor político de la comunidad. Quiere decirse que se proponía el replanteamiento de las instituciones democráticas, desde el diseño de estructuras y métodos de gestión más descentralizados y democráticos, es decir, desde la realidad desnuda e inmediata de los sujetos, desde la historicidad (finitud) de sus condiciones sociales. Por eso, ofrecía más participación en la resolución dinámica y mutualista de los problemas, más fines públicos donde antes no existían. Con semejante vocación - fruto de un amplio proceso de renovación interna, hasta entonces desconocido, en la izquierda británica ${ }^{22}$ - era lógico que desde el GLC se cuestionara activamente el papel del Estado ${ }^{23}$ en la satisfacción de las necesidades cotidianas de la ciudadanía ${ }^{24}$. Las relaciones entre éste y la sociedad respondían, desde la óptica de quienes hicieron posible la experiencia laborista en el gobierno londinense, a unos parámetros muy alejados de los que habían regido las consignas de la izquierda oficial europea. Si el Estado era una forma de redistribuir recursos y poder, la distribución del poder entrañaba un compromiso público con la autonomía de la ciudadanía y la toma democrática de decisiones fuera de las burocracias del Estado. Éstas seguían siendo el rastro visible de buena parte de los problemas que aquejaban a los grupos más indefensos de la ciudad. Sus profesionales seguían estando vincu-

21. Temas como la igualdad de oportunidades, la discriminación positiva y los compromisos con los grupos marginados eran fundamentales. Todos estos asuntos eran llevados a las conferencias regionales del Partido Laborista. Véase FINCH, N., MAKANJI, N., «Accountability to Whom?», Briefing National Supplement, febrero 1984, p. 8.

22. El Partido Laborista — como otros partidos de la izquierda europea - estaba fuertemente condicionado por ideas de centralismo democrático, las cuales se traducían en el planteamiento consistente en que una centralización administrativa alta era fundamental de cara a la construcción y consolidación del Estado de bienestar. Las estructuras y organizaciones del Partido Laborista y de los sindicatos no reflejaban los cambios sociales. Ello suponía un atraso constante frente a la acción de las organizaciones del capital. La consecuencia era no lograr afirmar una oposición eficaz generadora de alternativas que asumieran la opinión de la mayoría de la gente (véase GLC, London calling. The future of London's Government, GLC, Londres, 1986). Sin embargo, la nueva estrategia de los actores involucrados en el GLC se basó en un proceso de reflexión anterior que incluía prácticas como las de Lucas Aerospace o textos como el anteriormente citado del London Edinburgh Weekend Return Group, In and Against the State. The London Edinburgh Weekend Return Group. A Working Group of the Conference of Socialist Economists, op. cit., p. $77 \mathrm{y} \mathrm{s.}$

23. Hoy en día, parece que la única manera de criticar al Estado es desde las teorías neocontractualistas, que optan por el desmantelamiento de los servicios públicos, lo que conlleva la privatización de posibles espacios de decisión.

24. En Gran Bretaña, la Administración local se creó como una medida de emergencia con la idea de resolver los problemas que se derivaron de la revolución industrial, por ello no se puede afirmar que se tratara de una medida descentralizadora en el seno de una dinámica democrática. Fue un gobierno conservador quien creó la Administración local para Londres tras un pacto con Joseph Chamberlain, y nunca, históricamente, cuestionaron el poder de las administraciones locales, mientras que éstas sirvieran los mismos objetivos que abanderaban los conservadores. 
lados a los sectores más privilegiados de la población, es decir, a las clases dominantes. La solución parecía clara. Había que limitar el poder de las burocracias públicas y sus administradores, para dar paso a continuación a asociaciones de vecinos, de sindicatos, de asociaciones de mujeres y otros grupos sociales. Había que institucionalizar la conversación y la acción públicas a nivel local. Todo ello se completó con una política que subsidiaba las iniciativas de dichos grupos sociales ${ }^{25}$.

Aunque estas políticas de resituación de la conversación y la acción pública se llevaron a cabo con todos los grupos sociales, incidieron de manera especial en aquellos colectivos tradicionalmente olvidados de las políticas más generales del laborismo ${ }^{26}$, históricamente circunscritas en torno a sectores muy específicos de la clase obrera. Temas como el racismo o la discriminación hacia las mujeres y los homosexuales habían sido siempre postergados en la agenda política. Sin embargo, el trabajo del GLC con estos grupos sobrepasó las esperanzas. Fue tan imaginativo y enérgico, que acabó cristalizando en dos de los mayores productos intelectuales que nos legó el GLC:

- The London Industrial Strategy (1985). Básicamente, consistía en un proyecto industrial a gran escala para Londres y su área metropolitana, que daba entrada a todos estos colectivos y aportaba soluciones tan creativas a los problemas sociales, como la producción socialmente útili 7 , el auténtico leitmotiv de esta nueva izquierda: democratizar a la sociedad para transformar las relaciones de producción injustas.

- London Labor Plan (1986). Fue, en realidad, el complemento que requería el London Industrial Strategy. Respondía a la necesidad de actualizar y reconfigurar la economía londinense, implicando a la ciudadanía en los procesos de un proyecto económico alternativo El eje del proyecto descansaba sobre dos ideas: la dignificación y la democratización radical del trabajo en un contexto de relaciones económicas justas ${ }^{28}$.

Como era de prever, a esta estrategia se fueron sumando pequeñas y medianas empresas, que reforzaron la base social de los administradores municipales,

25. Tal y como había sido propuesto por el London Edinburgh Weekend Return Group.

26. Como se ha señalado, la descentralización tenía como eje la distribución de poder entre las clases y los grupos más deprimidos, marginados y explotados de la sociedad. Ello exigía presentar soluciones reales a los problemas concretos de la gente, ofreciendo vías políticas alternativas al proyecto político que imperaba en Gran Bretaña y Europa, e incluyendo a mujeres, a minorías, a minusválidos y al movimiento de gays y lesbianas. Véase SOTO, P., «Entrevista a Ken Livingstone», Madrid. Territorio, Economía y Sociedad, n. ${ }^{\circ}$ 38, marzo, 1987, p. 23-24.

27. La producción socialmente útil es un modelo productivo diferenciado del keynesianismo o el monetarismo. Para la producción socialmente útil, lo importante no es maximizar el beneficio, sino producir de acuerdo con las necesidades sociales reales.

28. WAINWRIGHT, H., SOTO, P., «La nueva política del GLC en materia de reindustrialización, tecnología y empleo», en Alfoz, op. cit., p. 36-55. 
lo que supuso un cambio sin precedentes en las estructuras tradicionales del laborismo ${ }^{29}$. Claro que las tensiones no tardaron en aparecer entre quienes se adherían a esta potente propuesta política, con sus instituciones y sus horizontes alternativos, y la dirección del partido laborista, respaldada por la prensa y los sectores públicos más tradicionales. Lo cual, lejos de bloquear el cambio, facilitó la interlocución democrática y dinamizó el tejido social de la ciudad. Los colectivos comenzaron a participar en las políticas de la ciudad como jamás lo habían hecho antes y las tensiones que se escenificaron en la vida política de Londres, ya fueran externas - piénsese en la acritud de la prensa sensacionalista con ocasión de la creación del Comité de Mujeres - o internas — del propio Comité de Mujeres entre mujeres negras y blancas, etc.- - en lugar de bloquear los cambios, lo cierto es que acicatearon el compromiso crítico de los londinenses con el funcionamiento democrático de unas instituciones, que ahora visualizaban alternativas a la gestión tradicional de los asuntos públicos e involucraban a la ciudadanía.

Claro que el GLC no se significó sólo por sus grandes proyectos. La experiencia del GLC estuvo jalonada por múltiples iniciativas y realizaciones. Una de las más populares fue la encaminada a regular el transporte público de Londres. Nada más alcanzar el poder, una de sus primeras acciones de gobierno fue la reordenación frontal (para mejorar) del servicio público de transporte y la reducción de sus precios y tarifas. No en vano era ésta una de sus promesas electorales y, quizás, uno de los reclamos decisivos en la victoria de Ken Livingstone. El compromiso consistía en disminuir las tarifas en un $25 \%{ }^{30}$ y en estimular el uso de este tipo de transporte. Se diseñaron bonos de viaje unitarios para autobuses y metro, se estimuló el transporte ferroviario en detrimento del autobús, se modernizaron las estaciones y se mejoraron los servicios de información y atención a los usuarios. También se adoptaron medidas encaminadas a satisfacer las demandas de colectivos de mujeres, de asociaciones de vecinos y de minusválidos, tales como el subsidio a éstos últimos del uso del radiotaxi; la ampliación de los servicios de taxi o autobús a zonas inseguras, donde eran habituales el asedio y las agresiones a las personas; el diseño de autobuses más adaptados a las mujeres que viajaban con niños o con la cesta de la compra, y la restricción prácticamente total de la entrada de camiones de gran tonelaje mediante el establecimiento de controles muy expeditivos sobre el estacionamiento en el centro ${ }^{31}$. El resultado sobrepasó las expec-

29. Livingstone, K., Livingstone Labour. A Programme for the Nineties, Londres, Unwin Hyman, 1989 , p. 89.

30. En realidad, el plan de bajada en las tarifas del transporte lo diseñó Andrew McIntosh. Incluso había posturas a favor de la gratuidad total del transporte, como la de Norman Howard (Whitehouse, W., GLC: The Inside Story, Middlesex, James Lester Publishers, 2000, p. 111).

31. Con el regreso de Livingstone como alcalde al consistorio londinense, se ha vuelto a tomar una medida similar consistente en limitar el uso del coche en el centro de la ciudad (The New York Times Magazine, 20 de abril de 2003). Las revistas saludaron esta medida como revolucionaria, ignorando que ya fue llevada a cabo por la misma persona dos décadas antes. Por 
tativas. Se incrementó el número de usuarios, disminuyó el uso del vehículo privado en un $10 \%$, con el consiguiente alivio en las congestiones de tráfico y la reducción de accidentes. Y lo que fue todavía más sorprendente, las cuentas públicas experimentaron un superávit de 36 millones de libras ${ }^{32}$.

Nunca hubieran imaginado los promotores de estas iniciativas que, en diciembre de 1981, la Cámara de los Lores declarase, en un veredicto muy controvertido que luego se confirmaría en apelación ${ }^{33}$, ilegales y excesivos los subsidios que el Gobierno de la ciudad de Londres había diseñado para sus políticas de transporte, también conocidos como Fares Fair. El siguiente paso fue privar, en 1984, al GLC del London Transport y atribuir esa competencia al London Regional Transport, adscrito a la Secretaría de Estado para el transporte del gobierno central. A continuación, se procedió a la desregulación del transporte público ${ }^{34}$. Este bloque de medidas fue el producto de una estrategia que se venía gestando desde 1980, cuando la Local Government Planning and Land Act confirió al gobierno central mayores cuotas de control sobre el gasto de las autoridades locales ${ }^{35}$. La sinceridad expeditiva de tales medidas pronto se escenificaría en el sector público de transporte: en el aumento de las tarifas entre un 10 y un 25 por ciento; en el recorte de los subsidios; en la introducción de operadores privados con capacidad para competir con el servicio público en las mismas rutas, y en la desregulación laboral del personal de transporte, que asistía a la reducción de sus pensiones y puestos de trabajo ${ }^{36}$.

Otro de los espacios paradigmáticos de las prácticas del GLC fue el cultural. Se tuvo especial cuidado en llevar el arte a todos los barrios de la ciudad - en claro contraste con esa otra política cultural que anticipa en sus realizaciones la inversión en grandes recintos de lujo- . Se abrieron al público numerosas salas de conciertos, museos y galerías de arte, que eran gratuitas.

otra parte, no podemos olvidar las reformas que, en el campo del urbanismo, llevó a término el GLC. Digamos que comenzó con la equiparación en la provisión de equipamientos urbanos, frenando la especulación y la construcción de oficinas en barrios obreros cerca del centro. Se impusieron controles muy estrictos sobre la localización de nuevas oficinas y centros comerciales. Cuando el gobierno apoyó un plan para que el viejo barrio de los muelles de Londres se reconvirtiera en una zona de oficinas y de residencias de lujo con aeropuerto, el GLC puso a todos sus servicios técnicos, poderes urbanísticos y financieros a disposición de los sindicatos y las asociaciones de vecinos, que buscaban una solución más apropiada a las necesidades de la gente del barrio (Livingstone, K., Livingstone's Labour. A Programme for the Nineties, op. cit., p. 201).

32. Labour Research Department, Rate Capping \& Abolition. Councils in Danger, Londres, LRD Publications, 1984, p. 24.

33. Desde el GLC, se argumentó que los lores estaban ayudando al Partido Conservador en sus políticas neoliberales de reducción del gasto público (CARvel, J., Citizen Ken, Londres, Chatto \& Windus. The Hogarth Press, 1984, p. 46).

34. La justificación para ese cambio radicó en la acusación, por parte de la Secretaría de Estado de Transporte, de que los servicios de transporte del GLC eran ineficientes y no económicos (véase GLC, The London Industrial Strategy, Londres, GLC, 1985).

35. Coates, D., Johnston, G., Socialist Strategies, Oxford, Martin Robertson, 1983, p. 212.

36. Labour Research Department, Rate Capping \& Abolition. Councils in Danger, Londres, LRD Publications, 1984, p. 24. 
Se fomentó la música popular y multiétnica y se promocionaron las discográficas locales, con el objeto de que fueran los ciudadanos quienes crearan su propia cultura musical ${ }^{37}$. También se subsidiaron centenares de grupos locales de teatro, música y baile, corriendo con los gastos de la organización de festivales en la ciudad. De hecho, los grupos locales de teatro se habían significado desde la década de los sesenta por su capacidad para concienciar políticamente a los ciudadanos ${ }^{38}$.

La política económica fue otro de sus caballos de batalla. Digamos que consiguió cristalizar en proyectos de la envergadura como los reseñados LIS o el LLP. Pero, ya en sus primeras actuaciones en política industrial, se lograron crear numerosos puestos de trabajo, frente a la tónica de desempleo y exclusiones de aquellos años. Y lo hizo de tres maneras distintas: (1) aumentando y mejorando la calidad de los servicios públicos; (2) respaldando las iniciativas de asociaciones locales populares, grupos de mujeres, asociaciones de gays y lesbianas, minorías étnicas y asociaciones de vecinos y minusválidos, con lo que llegó a crear, con esta iniciativa, unos seis mil puestos de trabajo, y (3) facilitando la reconversión de pequeñas y medianas empresas y cooperativas, a través de préstamos y subsidios negociados con las plataformas sindicales, de modo que la reconversión no implicara reducciones salariales o de plantilla, sino que se tradujera en la utilización de nuevas tecnologías y otros métodos de producción, que a su vez repercutieran en la competitividad de los productos ${ }^{39}$.

Claro que, junto a estas estrategias orientadas a revitalizar el tejido industrial londinense, que con ser importantes no saciaban sus expectativas de transformación histórica de las condiciones de producción, el GLC puso en escena su último hallazgo, un proyecto muy perspicaz y revolucionario, al tiempo que desconocido en el ámbito de las relaciones de producción: la producción socialmente útil. Básicamente, consistía en una serie de experiencias locales —algu-

37. Ward, M., Petit, P., Introduction, en GLC, The State of the Art or the Art of the State, Londres, GLC, 1985, p. 5-7.

38. No por casualidad, el Reino Unido ha sido uno de los emplazamientos europeos donde este movimiento de teatro popular socialista tuvo una mayor importancia. En este sentido, véase ItZIn, C., Stages in the Revolution. Political Theatre in Britain since 1968, Londres, Methuen, 1982. Para Catherine Itzin, si bien el teatro no puede por sí cambiar el mundo (de hecho, el teatro político fracasó en muchos de sus objetivos divulgativos), sí puede contribuir a abrir vías para que los colectivos que pueden, lo hagan.

39. Livingstone, K., Livingstone's Labour. A Programme for the Nineties, op. cit., p. 182. Éste fue el comienzo de la gestación de lo que hoy es una de las aspiraciones del movimiento de izquierda en el espacio transnacional: tratar de sumar apoyos entre asociaciones, sindicatos y ayuntamientos con el fin de poder dar una respuesta coordinada a la lucha que el capital transnacional plantea a los municipios del mundo y sus indudables repercusiones en el plano jurídico, social y ambiental. En el GLC estaba presente la idea de unión con otros movimientos de izquierda en el espacio transnacional. La disyuntiva era clara a los ojos del GLC: actuar para lograr ser uno de los países explotadores con una posición mejor, o trabajar por un sistema más justo para los ciudadanos del primer mundo y de los países empobrecidos. Véase ídem, p. 183. 
nas de las cuales, como Lucas Aerospace, tuvieron tiempo de influir en la vida social de Londres- orientadas a democratizar el funcionamiento de la economía. Quiere decirse que es un modelo productivo alternativo al modelo de producción capitalista, que, como sabemos, se sostiene merced a su sorprendente elasticidad como sistema económico preestructurado y a su eficacia en maximizar la obtención de beneficios. La producción socialmente útil, en cambio, promueve la satisfacción de necesidades socialmente útiles.

Desde luego, es una idea compleja, entre otras cosas porque no existe un proyecto, un esquema que pueda encuadrar este modelo productivo en sus límites precisos. Sin embargo, nos sitúa en la base de prácticas políticas sólidas y alternativas frente a los desafíos de la lógica del capital. Desde luego, la idea central es frontal y directa: hay que producir colectivamente aquellas cosas que necesitamos o, dicho de otro modo, no han de producirse bienes o servicios frívolos, peligrosos o que puedan provocar la muerte. La racionalidad económica hegemónica - la capitalista - no tiene como fin último la producción de bienes y servicios, sino tan sólo la obtención ilimitada de beneficios. El beneficio deviene en la única medida de la producción ${ }^{40}$. No olvidemos que la pauta constitutiva de la expansión del sistema mercantil reside precisamente en la mediación mercantil como sostén «antropológico de la humanidad ${ }^{41}$. Cuantos más sectores — sanidad, educación — y actividades —energía, tecnologías, biomedicina, farmacología, etc. - se expongan a ese proceso de cuantificación y de valoración en términos de rentabilidad, tanto mejor para un sistema cuya fuerza se basa en esta experiencia directa, a veces brutal, de cálculo racional de eficiencia y/o rentabilidad. Por otra parte, el sistema de producción capitalista se ha esforzado en metabolizar las reacciones y la crítica a su modo socioeconómico de ser - falta de autonomía en el trabajo, ausencia de iniciativas, escasez creativa- por medio de una organización del trabajo «en red» trenzada por discursos de gestión empresarial iniciados en la década de 1990.

Por el contrario, la producción socialmente útil pretende democratizar el funcionamiento de la economía, dotando a las relaciones productivas de libertad, capacidad creativa y cooperación en el trabajo. Pongamos un ejemplo: en la actualidad apenas si se destina un 3\% de los recursos disponibles para la investigación contra el sida a la elaboración de una vacuna eficaz. Desde la óptica del mercado capitalista, no existe ningún tipo de objeción. Los fármacos son una fuente inestimable de beneficios para las compañías farmacéuticas. El descubrimiento y la comercialización de una vacuna eficaz contra el sida reducirían drásticamente la expectativa de beneficios. Empero, la utilidad social del descubrimiento de una vacuna como ésta sobrepasaría con creces las costosas terapias con fármacos específicos, que hacen del sida una enfermedad crónica en

40. Collective Design/Projects (ed.), Very nice work if you can get it. The Socially Useful Production Debate, Nottingham, Spokesman, 1985, p. 13-15.

41. SAMI NAÏR, El imperio frente a la diversidad del mundo (título original L 'empire face a la diversité, R. H. Mondadori, 2003, trad. a cargo de Sara Barceló y María Cordón), Barcelona, Círculo de Lectores, 2003, p. 20. 
aquellos lugares donde los afectados pueden costearse los tratamientos. La producción socialmente útil priorizaría la vacuna sobre los fármacos, es decir, invertiría la tendencia.

Claro que con esto no queremos decir que se trate de un modelo keynesiano. Y decimos «keynesiano» porque, en estos días de desregulación (del proceso productivo) y de desformalización (de los derechos de los trabajadores), el monetarismo y el keynesianismo siguen encasillando el debate económico, merced al Consenso de Washington y a sus políticas neoliberales. Las posiciones keynesianas se identifican ahora con la izquierda "menos moderna" y la tercera vía sigue perforando ideológicamente a la socialdemocracia europea. Pero, con sus diferencias y sus cercanías, lo cierto es que ambos confían en la intervención política como remedio a los problemas que acechan a los mercados, y poco o nada sugieren acerca de la producción, la ojiva profunda de la economía.

Ignorada por muchos economistas, la producción ha quedado en manos de ingenieros, asesores financieros o consultores y directores generales de producción. Éstos tienen dos preocupaciones fundamentales: en primer lugar, el proceso físico de producción, con el plan de la planta, la calidad en el trabajo, el adecuado comportamiento de los equipos y la maquinaria, y, en segundo término, la productividad, la rapidez en el trabajo, el esfuerzo de los trabajadores, la adaptación de los equipamiento a los cambios en la demanda y la incorporación de las nuevas tecnologías ${ }^{42}$.

Pero estos elementos que se inscriben en el centro de cualquier economía - es en el proceso de producción donde se dirimen tanto la competitividad del producto como la expectativa de beneficios-, no son decisivos para unas políticas tan confiadas en su capacidad de influencia en los mercados como solución a sus desequilibrios, como escasamente receptivas al espacio de la producción. Claro que la realidad de los problemas que hoy nos acompañan -el funcionamiento de los servicios públicos, el crecimiento del desempleo, los procesos de desdemocratización del trabajo y la producción y el incumplimiento sistemático de promesas y necesidades-, se ha encargado de evidenciar el fracaso de este tipo de políticas en el diseño de las condiciones de bienestar de la población ${ }^{43}$. Aunque también cabría decir que han triunfado, que no han fracasado en esto de fortalecer los intereses de lobbies y poderosos (monetarismo) o en esto de legitimar burocracias injustas (keynesianismo).

Como contraste, la producción socialmente útil no asume como punto de partida las prioridades o los equilibrios del capital. Antes al contrario, promueve el trabajo de todos y para todos (necesidad social), el «trabajo útil» que diría William Morris ${ }^{44}$, la economía del trabajo. Sus patrones alternativos fueron: (1) la innovación tecnológica (technology networks); (2) la cooperación

42. GLC, The London Industrial Strategy, op. cit., p. 12 y s.

43. Ídem.

44. Citado por GorZ, A., «El socialismo difícil», en VV. AA., La sociedad industrial contemporánea, Madrid, Siglo XXI, 1977, p. 127-129. 
con la universidad; (3) la atención a las necesidades y aspiraciones de los trabajadores, con el objeto de que su trabajo fuera eficaz y provechoso, y (4) la inversión en el tejido productivo tradicional de Londres, pero desde nuevos valores como la cooperación y la atención de necesidades sociales. Junto a ello, fue un elemento clave la revisión del Plan de Desarrollo del GLC, para evitar que se discriminara a mujeres, minorías y cualesquiera otros grupos rayanos en la exclusión.

\section{A modo de conclusión}

La magnitud revolucionaria de ese experimento político en el área metropolitana de Londres alertó, como no podía ser de otra manera, al gobierno neoliberal thatcherista. A medida que se dejaban sentir sus actuaciones en la población, la experiencia política del GLC comenzaba a cristalizar. De ahí que la respuesta no se hiciera esperar. Había que incrementar la presión sobre los gobiernos locales para menguar su autonomía en materia económica y social. Básicamente, el objetivo del gobierno de Thatcher consistía en recortar el presupuesto en servicios públicos esenciales como la educación, el transporte, el mantenimiento de las vías públicas o la vivienda. La revolución conservadora de los ochenta estaba allí y nacía con voluntad de ahorro, control sobre los municipios y recortes ${ }^{45}$.

La sinceridad cruenta de sus propuestas políticas se visualizó con fuerza en el este de Londres. Las diferentes fases de reestructuración del capitalismo acarrearon desajustes y tragedias en esta zona de la ciudad: desempleo, trabajos precarios, retroceso sindical, deterioro del sector público. Entretanto, el gobierno de Thatcher se jactaba de la inexistencia de alternativas, convencido del realismo y la racionalidad de sus políticas. En aquellos momentos, la única salida posible a los problemas que se escenificaban con la crisis pasaba por la especulación y la privatización de los espacios devastados. La respuesta del GLC fue la de contrarrestar sus efectos en el este londinense con inversiones públicas, bloqueando la trampa especulativa en esta zona de Londres ${ }^{46}$. De hecho, desde que accediera al gobierno de la ciudad en 1981 con el apoyo elec-

45. Se trataba de recortar para luego ahorrar. Sin embargo, el ahorro no fue tal. Un estudio encargado a la empresa Coopers \& Lybrand reveló que, en el caso de los seis condados metropolitanos incluidos en el proyecto de abolición junto al GLC, no se ahorraría dinero. El ahorro en el caso del GLC vendría dado por el recorte radical en los servicios públicos. Una estrategia de resistencia promovida fue que el líder o alcalde del GLC y su equipo dimitieran, a fin de que se llevara a cabo una nueva elección donde se votara sobre la abolición. Esa alternativa era apoyada incluso por George Tremlett, jefe de los conservadores en el GLC. Por otra parte, el tejido asociativo del Gran Londres apoyaba la continuidad del GLC. La gran mayoría de las asociaciones estaban en contra de la abolición - 1.470 frente a 190: Labour Research Department, Rate Capping o Abolition. Councils in Danger, op. cit., p. 2-20. Cfr. LBA, Final Consequences of GLC Abolition, Londres, LBA, 1991. En este texto se desarrolla la tesis del ahorro desde una perspectiva conservadora.

46. GLC, The East London File, Londres, GLC, 1982, p. 40-41. 
toral del $42 \%$ de los londinenses, el GLC siguió contando, pese a las dificultades, con el respaldo mayoritario de los ciudadanos hasta su desaparición en 1986.

La actitud fuerte y acre de Thatcher y su gabinete para con sus propuestas de participación radical, las resistencias de determinados sectores del Partido Laborista, el escaso beneplácito a sus políticas de los grandes medios o el propio escepticismo social, no consiguieron ensombrecer la popularidad de sus iniciativas. Con todo, no hubo quien detuviera el alud ${ }^{47}$. En 1986, el GLC dejaba de existir entre golpes de poder y el silencio cómplice de muchos estamentos del propio Partido Laborista ${ }^{48}$, que no compartían buena parte de sus imaginativas políticas. No se atrevieron a identificarse con estas políticas que claramente desbordaban las tradicionales estrategias del parlamentarismo y el sindicalismo e hicieron muy poco por impedir la abolición. Es más, en asuntos como el antirracismo y las políticas sexuales, siempre se mantuvo alejado con objeto de preservar su moderada y parlamentaria «respetabilidad» ${ }^{49}$.

Hay que decir que esta política de supresión del GLC no se debió a que el gobierno central se sintiera amenazado. Nada más lejos de la realidad. Fue un paso más de un proceso de reformas sucesivas sin debate previo orientado a tomar el control de todos los resortes del poder — mediante la Rates Act de 1984- y aniquilar la autonomía local, es decir, a propiciar un estado unitario y neoliberal. Digamos que fue el comienzo de la gran revolución neocapitalista ${ }^{50}$. Incluso de los contenidos del informe sobre el GLC (Streamlining the

47. Las encuestas antes de la abolición ponían de manifiesto que las razones esgrimidas por el gobierno eran inconsistentes. En su punto más álgido de la campaña antiabolición, el $74 \%$ de los londinenses era contrario a la misma. Un año después de la abolición, el Daily Mail realizó una encuesta y, en ella, se reflejó que el 59\% de los londinenses deseaban la restauración del GLC. El proceso legislativo de abolición del GLC fue largo y complicado. Consistió en dos Acts del Parlamento: la primera, la Local Government (Interim Provisions) Act, de 1984 (también llamada Paving Act). A ésta siguió la Abolition Act. The Local Government Act, de 1985. Dentro de este proceso, no se puede dejar de olvidar la Transport Act, de 1984, que dejó al GLC sin uno de sus principales poderes - la financiación y la gestión del metro y los autobuses- . La Paving Bill fue anunciada en el discurso de la Reina de 1984 y se introdujo en 1984. Recibió el Royal Assent en julio de 1984. La Abolition Bill se introdujo en noviembre de 1984 y recibió el Royal Assent en julio de 1985. La postura que adoptó el GLC fue defensiva y, en última instancia, si no se podía impedir la abolición, al menos se intentó que se respetaran los empleos (WALLER, R. (comp.), Moulding Political Opinion, Nueva York, Croom Helm, 1988, p. 107-109).

48. Durante la campaña electoral de 1987, los ataques contra el GLC y otros concejos laboristas realizados por la derecha no fueron contestados por los líderes laboristas (GUNN, S., Revolution of the Right, Londres, Pluto Press, 1989, p. 108-109).

49. GunN, S., Revolution of the Right, op. cit., p. 108-109.

50. El GLC y su abolición fue el comienzo de la gran revolución neocapitalista de los ochenta, tal y como constata uno de los libros clave que describe dichos cambios (véase JENKINS, P., Mrs. Thatcher's Revolution. The Ending of the Socialist Era, Cambridge, Harvard University Press, 1988, p. 180-181). La necesidad de la abolición era compartida por los miembros del partido conservador. En lo que había divergencias era en la manera de llevarla a cabo, ya que se trataba de un órgano elegido por el pueblo. 
Cities, publicado en octubre de 1983) no se infería su eliminación. Como tampoco se alcanzarían los beneficios que se pretendían alcanzar con la abolición. La estrategia del gobierno conservador no llevaba las trazas de ser ambigua en este remate: se trataba de abolir sin más el GLC ${ }^{51}$.

Podríamos afirmar que las alternativas del GLC aceleraron en cierta forma el proceso de reforma neoliberal del Reino Unido de la mano de actitudes escasamente democráticas (autoritarias), que, en cualquier otra circunstancia, se hubiesen querido evitar. Actitudes y políticas que hoy se llevan a cabo mediante planes de estabilidad y bancos centrales, pero que, en aquellos días, se escenificaban de manera diferente, mediante la adopción de medidas tan expeditivas como el desmantelamiento del GLC ${ }^{52}$. No ha de resultar extraño, por tanto, que Robin Pauley, el hombre de confianza de Thatcher, declarara al Financial Times, el 5 de mayo de 1984, que el GLC representaba el socialismo moderno y que, en consecuencia, debía ser suprimido. Después de cinco años, el gobierno central y gracias, en gran medida, al triunfo en la guerra de las Malvinas (que insufló aire a la maltrecha popularidad del gobierno neoliberal), el gobierno conservador abolió, contra el grito mayoritario de los londinenses, el GLC ${ }^{53}$.

Ha transcurrido el tiempo. El gobierno local elegido por las urnas ha regresado bajo el nombre de Greater London Authority, pero ya nada permanece igual. Ahora el gran reto para Livingstone y su equipo es bloquear los procesos de privatización del metro. Sus poderes son muy limitados, mucho más que en 1981, y el contexto donde desarrolla la acción ha perdido la ilusión y el empuje de aquellos años. Hoy debemos ir más lejos, trasponer pasos hasta ahora prohibidos, si queremos rehacer nuestras esperanzas de democracia. Quizás Porto Alegre.

\section{Bibliografía}

BARATTA, G. (2003). Las rosas y los cuadernos: El pensamiento dialógico de Antonio Gramsci. Barcelona: Bellaterra.

Barnett, A. (1986). «Whistling in the Wind?». New Socialist.

CAmpbell, B.; JacQues, M. (1986). «Goodbye to the Greater Londres Council». Marxism Today.

CAnetTi, E. (2000). Masa y poder. Barcelona: Muchnik Editores.

Carvel, J. (1984). Citizen Ken. Londres: Chatto \& Windus. The Hogarth Press. Chun, L. (1993). The British New Left. Edimburgo: Edinburgh University Press. Coates, D.; Johnston, G. (1983). Socialist Strategies. Oxford: Martin Robertson.

51. Stonefrost, M., The Future of London Government, en Leach, S. (ed.), The Future of Metropolitan Government, Institute of Local Government Studies, Birmingham, University of Birmingham, 1984, p. 12-17.

52. Flynn, N., Leach, S., Vielba, C., Abolition or Reform? The GLC and the Metropolitan County Councils, Londres, George Allen \& Unwin, 1985, p. IX-X.

53. Campbell, B., Jacques, M., "Goodbye to the Greater London Council», Marxism Today, April, 1986, p. 10. 
Collective Design/Projects (ed.) (1985). Very nice work ifyou can get it: The Socially Useful Production Debate. Nottingham: Spokesman.

FIeldiNG, N.; SeYD, P. (1984). «Cities in the Revolt». New Socialist.

Finch, N.; MAKANJI, N. (1984). "Accountability to Whom?». Briefing National Supplement.

Flynn, N.; Leach, S.; Vielba, C. (1985). Abolition or Reform? The GLC and the Metropolitan County Councils. Londres: George Allen \& Unwin.

GLC (1986). Londres calling: The future of Londres's Government. Londres.

- (1982). The East Londres File. Londres.

- (1985). The Londres Industrial Strategy. Londres.

GorZ, A. (1977). «El socialismo difícil». En: VV. AA. La sociedad industrial contemporánea. Madrid: Siglo XXI.

GunN, S. (1989). Revolution of the Right. Londres: Pluto Press.

GyForD, J. (1984). «From Community Action to Local Socialism». Local Government Studies, 10.

HIPKIN, B. (1984). "Writing on the Wall for the GLC». Marxism Today.

ITZIN, C. (1982). Stages in the Revolution: Political Theatre in Britain since 1968. Londres: Methuen.

Jenkins, P. (1988). Mrs. Thatcher's Revolution: The Ending of the Socialist Era. Cambridge: Harvard University Press.

KNIGHT, C.; WISE, V. (1982). «Editorial: Taking to the Streets». Londres Labour Briefing. Labour Research Department (1984). Rate Capping \& Abolition: Councils in Danger. Londres: LRD Publications.

LBA (1991). Final Consequences of GLC Abolition. Londres.

LivingSTONE, K. (1989). Livingstone Labour: A Programme for the Nineties. Londres: Unwin Hyman.

Livingstone, K., Ali, T. (1984). Who's afraid of Margaret Thatcher. Londres: Verso. Mackintosh, M.; Wainwright, H. (ed.) (1987). A Taste of Power. Londres: Verso. SAMI NAïr. (2003). El imperio frente a la diversidad del mundo. Título original: L'empire face a la diversité. R. H. Mondadori, 2003. Traducción a cargo de Sara Barceló y María Cordón. Barcelona: Círculo de Lectores.

Soto, P. (1987). «Entrevista a Ken Livingstone». Madrid: Territorio, economía y sociedad, n. 38 .

Stonefrost, M. (1984). «The Future of Londres Government». En Leach, S. (ed.). The Future of Metropolitan Government. Birmingham: Institute of Local Government Studies. University of Birmingham.

"The Women's Movement and The Labour Party: An Interview with Labour Party Feminists». Feminist Review, 16, 1984.

Wainwright, H. (1987). Labour. A Tale of Two Parties. Londres.

Waller, R. (comp.) (1988). Moulding Political Opinion. Nueva York: Croom Helm. WARD, M. (1983). «Labour's Capital Gains: The GLC Experience». Marxism Today. Ward, M.; PetiT, P. (1985). «Introduction». En: GLC, The State of the Art or the Art of the State. Londres: GLC.

WheEn, F. (1985). The Battle for Londres. Londres: Pluto.

Whitehouse, W. (2000). GLC: The Inside Story. Middlesex: James Lester Publishers. 